\title{
The increasing concentration at industrial markets: the social welfare maximization and possible risks
}

\author{
Alexander Filatov ${ }^{1,2 *}$, and Yana Makolskaya ${ }^{2}$ \\ ${ }^{1}$ Far Eastern Federal University. School of Economics and Management, Vladivostok, Russia \\ ${ }^{2}$ Irkutsk State University, Institute of Mathematics, Economics, and Informatics, Irkutsk, Russia
}

\begin{abstract}
The paper considers impact of entry barriers on the social welfare. Despite the common opinion that entry barriers are always bad, the excessive number of firms means, all pros aside, duplicated fixed costs. It is shown that the socially effective number of firms is smaller than the equilibrium one for the wide spectre of demand and cost functions, and also for different strategies of companies' behavior. This proposition is satisfied for the homogeneous product markets where output of each company decreases when the number of firms increases, and competition gets stronger. But there is the considerable danger of the increasing probability of collusion in a situation of number of firms limitation. We show that collusion is less dangerous than duplicated fixed costs if the gap between the "choke price» and marginal costs is less than a certain critical value connected with the share of fixed costs. The empirical research on the base of the financial statistics of the biggest world corporations of different industries is carried out.
\end{abstract}

\section{Introduction}

Equilibrium states in economy are often socially ineffective. We can refer to different examples of the prisoner's dilemma, the tragedy of commons, insufficient financing of public good, negative selection moral hazard, and other problems of the contract theory. In all of them we need a special market design helps to decrease inefficiency. But we always should compare market failures and inefficiency of regulation taking into account the possible risks of agents' behavior change.

In the paper we will concentrate on the problems of market power. Using theoretical models and empirical data we will answer the following three questions: is there excessive or insufficient number of firms at a market in equilibrium, should we use regulation and what are the possible risks?

Most industries nowadays are high-concentrated markets where every producer maximizes profit taking into account a wide spectre of the competitors' behavior strategies from price wars to collusion. A lot of books and papers are devoted to the different aspects of such oligopoly markets. Among them we would emphasize classical monographs of Tirole [1], Shy [2], Carlton and Perloff [3], and the new standard of studying industrial organization, suggested by Belleflamme and Peitz [4]. We also made a survey [5] of different oligopoly models.

The main feature of oligopoly is a small number of strategic firms interacted at a market. But there is a significant difference between duopoly and oligopoly with, for example, ten firms. So the best strategies, equilibrium price and quantity, social welfare, and deadweight loss are strongly dependent on market concentration, and entry barriers created by the incumbent firms on the base of absolute cost advantages, increased returns to scale, access to resources and technologies limitation and government through the system of licenses and permissions for doing business.

There is a common opinion that entry barriers are always bad for society, because they decrease the number of firms, weaken competition, raise prices and decrease quantities. However we should understand that a lot of firms also mean duplicated fixed costs. Thus, free entry can lead to both situations: excessive and insufficient number of firms in equilibrium. The correct conclusion depends on the market structure, demand and cost functions, and features of strategic interaction between companies at a market.

It was shown [6;7] insufficient number of firms in equilibrium at monopolistic competition markets with differentiated product. It means that entry barriers at these markets are always bad. Particularly it is connected with consumers love for variety. But the opposite situation arises at homogeneous product markets, often having oligopoly structure. Von Weizacker [8] and Perry [9] proposed reasons for the desired limitation of excessive competition. Mankiw and Whinston [10] formulated some conditions (usually, though not always satisfied) under which this reduction would lead to the social welfare maximization.

At the same time even many empirical papers - for radio broadcasting [11], real-estate [12], investment foundations [13] cinema industry [14], etc. didn't convince society that entry barriers and reducing the

* Corresponding author: alexander.filatov@gmail.com 
number of firms at a market may be useful. This is partly connected with misconceptions initiated by the basic models of perfect competition where zero fixed costs lead to a definite conclusion «more firms is always better». Partly - with the really existing risks of possible modification of companies' behavior or welfare redistribution within society that can be unfavorable for the majority even when the total welfare increases. Let's consider some of these problems in the paper.

\section{The model}

Let's consider a homogeneous product market. We assume that there is monotonically declining inverse demand function $p=D^{-1}(Q)$. The cost functions of $n$ identical oligopolists are the same: $T C(q)=f+V C(q)$. Taking into account the number of firms and their interaction strategies we can find quantities $q(n)$ and a market price $p(n)=D^{-1}(n q(n))$.

The social welfare function consists of consumer surplus (integrated spread between the maximum willingness to pay given in the form of inverse demand function, and the current market price), and total profit of firms $S W=C S+n \pi(n)$ :

$$
S W=\int_{0}^{n q(n)} D^{-1}(q) d q-n(f+V C(q(n))) .
$$

If there are no entry barriers at a market, the equilibrium number of firms can be obtained from the zero profit condition

$$
\pi\left(n_{1}\right)=p\left(n_{1}\right) q\left(n_{1}\right)-f-V C\left(q\left(n_{1}\right)\right)=0 .
$$

Let's note that it's not just a theoretical fact. Bresnahan and Reiss on the basis of numerous data of the US food markets with fluctuating demand showed [15] that entry and competition really happens under such conditions.

Now it's possible to estimate how the number of firms impacts social welfare:

$$
\begin{gathered}
\frac{\partial(S W)}{\partial n}=\frac{\partial\left(\int_{0}^{n q(n)} D^{-1}(q) d q\right)}{\partial n}-f-\frac{\partial(n V C(q(n)))}{\partial n}= \\
=p(n)\left(q(n)+n \frac{\partial q(n)}{\partial n}\right)-f-V C(q(n))-n M C(q(n)) \frac{\partial q(n)}{\partial n}= \\
=\pi(n)+n(p(n)-M C(q(n))) \frac{\partial q(n)}{\partial n} .
\end{gathered}
$$

As noted above, the first term in this equation is equal to zero in equilibrium. Let's also assume that the firm quantities decrease in number of number of firms due to business-stealing effect

$$
\frac{\partial q(n)}{\partial n}<0
$$

and the price exceeds marginal costs of production

$$
p(n)-M C(q(n))>0,
$$

Then the second term and the whole derivative of social welfare at the equilibrium number of firms are negative:

$$
\frac{\partial(S W)}{\partial n}<0
$$

It means that for social welfare maximization the planner should decrease the number of firms with respect to their equilibrium quantity.

\section{Counterexample and discussion}

For most demand and cost functions, and strategies of firms' behavior the inequalities (1)-(2) are satisfied. But it's difficult to check the first one even when we know everything about the market. For example assumption (1) is not satisfied for simple case of Cournot model with inverse proportionality demand function and linear costs:

$$
p=\frac{a}{Q}=\frac{a}{q_{1}+\ldots+q_{n}}, T C_{i}\left(q_{i}\right)=c q_{i}+f .
$$

Let each producer maximize profit

$$
\pi_{i}=p q_{i}-c q_{i}-f=\frac{a q_{i}}{q_{1}+\ldots+q_{n}}-c q_{i}-f \rightarrow \max .
$$

Solving this problem for all symmetric firms we can find equilibrium prices and quantities:

$$
q^{*}=\frac{a(n-1)}{n^{2} c}, \quad Q^{*}=\frac{a(n-1)}{n c}, \quad p^{*}=\frac{n}{n-1} c .
$$

Firms' profits will be the following:

$$
\pi^{*}=\frac{a n}{n^{2}}-\frac{a(n-1)}{n^{2}}-f
$$

The equilibrium number of firms can be found from the zero profit condition:

$$
\pi^{*}=0, \quad \frac{a n}{n^{2}}-\frac{a(n-1)}{n^{2}}=f, \quad n_{1}=\sqrt{\frac{a}{f}}
$$

The social welfare function will be written as follows:

$$
S W=\int_{0}^{Q} \frac{a}{q}-c Q-n f=a \ln \frac{a(n-1)}{n c}-\frac{a(n-1)}{n}-n f .
$$

Let's obtain the derivative of social welfare and estimate its sign at $n_{1}$ :

$$
\begin{gathered}
S W^{\prime}=\frac{\partial(S W)}{\partial n}=\frac{a}{n^{2}(n-1)}-f, \\
S W^{\prime}\left(n_{1}\right)=S W^{\prime}\left(\sqrt{\frac{a}{f}}\right)=\frac{a}{\frac{a}{f}\left(\sqrt{\frac{a}{f}}-1\right)}-f=f \cdot \frac{2-n_{1}}{n_{1}-1} .
\end{gathered}
$$

So when $n_{1} \in(1 ; 2) S W^{\prime}\left(n_{1}\right)>0$, and the number of firms growth impacts positively on social welfare. It means insufficient number of firms in equilibrium. We can face this situation if $f>0.25 \alpha$, which happens under a very high level of fixed costs that doesn't allow more than two firms enter the market.

Generally we can say that it's rather the exception than the rule. It's similar to the anti-competitive markets [16] where firms with market power increase prices during demand reduction. They are rare, but can be. And there are also several more questions:

1. We said that it's always necessary to decrease the number of firms from the equilibrium level. But can we still state that the globally best for society number of firms is always smaller than the equilibrium one? 
2. What is happening if we face the real situation with heterogeneous firms, for example with firms having different cost functions?

3. How does the possible change of firms' behavior, for example collusion, impact the investigated market situation and social welfare?

4. How are the results connected with shares of fixed and variable costs, and what can we say about real markets on the base of empirical data?

The answer for the first question was given in [10]. Mankiw and Whinston proposed one more assumption

$$
\frac{\partial Q(n)}{\partial n}>0, \quad \lim _{n \rightarrow \infty} Q(n)<\infty .
$$

The assumption (3) means that equilibrium market output increases with the number of firms entering industry and approaches some finite bound. It provides the monotonic social welfare growth in situation when number of firms falls from the equilibrium to the optimum level, but it's also very difficult to identify if it's satisfied.

The second possible research direction is connected with firms' heterogeneity. In reality producers are very different even within one country. Moreover, contrary to a popular opinion that in each country some industries live well and obtain high profits, and the other ones are on the edge of survival, interindustry distinctions in the firms' productivity are much less essential, than distinctions within industry. Particularly it was shown [17] that the gap in productivity between the best $20 \%$ and the worst $20 \%$ of Russian enterprises within one industry is equal to 9-24 times. So we should take it into account.

The theoretical models for heterogeneous firms are much more complicated. Instead of number of firms we should use Herfindahl-Hirschman Index as a measure of market concentration. But first preliminary results show the similar conclusions: there are too many firms in equilibrium. Of course we have to assume that when some firms should exit the market it would be the worst ones, the most effective firms would stay on. Otherwise everything is possible. Nevertheless we won't focus on heterogeneity now. Let' consider in detail the last two questions: by-effects and possible risks of the concentration growth, and empirical evidence.

\section{Collusion and social welfare}

The by-effects of reducing the number of firms at a market can be connected with the possible change of their strategies, particularly with increasing probability of collusion. The principal theoretical and practical problems of the economics of cartels, collusion, and horizontal merger were in detail discussed in [18; 19], but the most important one is undoubtedly deadweight loss caused by reducing quantities under increasing prices. So let's assume that firms maximize their total profit by establishing monopolistic price and then divide profits among them. For linear Cournot model it follows $\pi=(a-b n q) q-c q-f \rightarrow \max , \quad a-2 b n q-c=0$,

$$
q^{*}=\frac{a-c}{2 b n}, Q^{*}=\frac{a-c}{2 b}, p^{*}=\frac{a+c}{2}, \pi^{*}=\frac{(a-c)^{2}}{4 b n}-f .
$$

The social welfare function will be

$$
S W=\frac{3}{8} \frac{(a-c)^{2}}{b}-n f .
$$

It should be noted that consumer surplus, total revenue and variable costs are independent from the number of firms, because prices and quantities coincide the monopolistic ones. So increasing the number of firms in a situation of collusion we just duplicate fixed costs and influence negatively on social welfare.

Let's consider the numerical example with demand $p=55-Q$ and total cost function $T C(q)=25+15 q$. As it's followed from the obtained above formulas, the equilibrium number of firms will be seven, but at the same time for social welfare maximization it should be three firms.

In the table 1 we will show individual and total market quantities, prices, profits, consumer surplus and social welfare for cases of equilibrium and socially effective number of firms, and also of monopoly. In the table 2 there is a similar information describing the market of cooperating firms

Table 1. Quantities, prices and social welfare in the model without collusion.

\begin{tabular}{|c|c|c|c|c|c|c|c|}
\hline $\boldsymbol{n}$ & $\boldsymbol{Q}$ & $\boldsymbol{Q}$ & $\boldsymbol{p}$ & $\boldsymbol{\Pi}$ & $\boldsymbol{C S}$ & $\boldsymbol{n \pi}$ & $\boldsymbol{S} \boldsymbol{W}$ \\
\hline $\mathbf{7}$ & 5 & 35 & 20 & 0 & 613 & 0 & $\mathbf{6 1 3}$ \\
\hline $\mathbf{3}$ & 10 & 30 & 25 & 75 & 450 & 225 & $\mathbf{6 7 5}$ \\
\hline $\mathbf{1}$ & 20 & 20 & 35 & 375 & 200 & 375 & 575 \\
\hline
\end{tabular}

Table 2. Quantities, prices and social welfare in the model with collusion.

\begin{tabular}{|c|c|c|c|c|c|c|c|}
\hline $\boldsymbol{n}$ & $\boldsymbol{Q}$ & $\boldsymbol{Q}$ & $\boldsymbol{p}$ & $\boldsymbol{\Pi}$ & $\boldsymbol{C S}$ & $\boldsymbol{n \pi}$ & $\boldsymbol{S W}$ \\
\hline $\mathbf{7}$ & 2,86 & 20 & 35 & 32 & 200 & 225 & 425 \\
\hline $\mathbf{3}$ & 6,67 & 20 & 35 & 108 & 200 & 325 & $\mathbf{5 2 5}$ \\
\hline $\mathbf{1}$ & 20 & 20 & 35 & 375 & 200 & 375 & 575 \\
\hline
\end{tabular}

We can see from the tables that after the number of firms decrease from seven to three social welfare increases from 613 to 675 (despite rising of prices and reduction of consumer surplus, firms' profits decrease at a greater extent). However, if collusion is possible, the cooperated firms by increasing prices and decreasing quantities to the monopoly level will reduce the social welfare function to 525 which is worse not only than socially effective value 675 , but than initial equilibrium state 613 . Further let's answer the question, whether the risk of collusion will always dominate the factor of fixed costs reduction.

Let's compare the social welfare in initial situation of equilibrium number of firms with no collusion and in possible under regulation situation of effective number of firms with collusion:

$$
\begin{gathered}
S W_{w o / c o l}\left(n_{1}\right)=\frac{1}{2} \frac{(a-c)^{2}}{b}+\frac{1}{2} f-\sqrt{\frac{(a-c)^{2} f}{b}}, \\
S W_{c o l}\left(n_{2}\right)=\frac{3}{8} \frac{(a-c)^{2}}{b}+f-\sqrt[3]{\frac{(a-c)^{2}}{b f} f} .
\end{gathered}
$$


Let's estimate under what range of parameters the new situation will be better than initial one, i.e. the inequality $S W_{\text {col }}\left(n_{2}\right)-S W_{\text {wo } / \text { col }}\left(n_{1}\right)>0$ is satisfied. By defining $x=(a-c)^{2} / b>0$ we will get

$$
S W_{c o l}\left(n_{2}\right)-S W_{w o / c o l}\left(n_{1}\right)=-\frac{1}{8} x+\frac{1}{2} f+\sqrt{x f}-\sqrt[3]{x f^{2}} .
$$

Let's analyze the function

$$
g(y)=\frac{S W_{c o l}\left(n_{2}\right)-S W_{w o / c o l}\left(n_{1}\right)}{x}=-\frac{1}{8}+\frac{1}{2} y+\sqrt{y}-\sqrt[3]{y^{2}},
$$

where $y=f / x=f b /(a-c)^{2}<1$.

The positivity of function $g(y)$ means that collusion is less dangerous than fixed costs duplication which we can face in equilibrium. Derivative of function $g(y)$

$$
g^{\prime}(y)=\frac{1}{2}+\frac{1}{2 \sqrt{y}}-\frac{2}{3 \sqrt[3]{y}}
$$

is always positive, it means that $g(y)$ is increasing monotonously. Taking into account that

$$
g(0)=-\frac{1}{8}<0, g(1)=\frac{3}{8}>0,
$$

we can state that the only root of function $g(y)$ lies in the interval of $[0 ; 1]$. By solving numerically the equation $g(y)=0$ we can find that $y^{*} \approx 0.064$. Going back to the initial variables we obtain, that $S W_{c o l}\left(n_{2}\right)-S W_{w o / c o l}\left(n_{1}\right)>0$ when the following inequality is satisfied:

$$
f>\frac{(a-c)^{2}}{2 b} 2 y^{*} \approx 0.128 \frac{(a-c)^{2}}{2 b} .
$$

It should be noted that if to forget about fixed costs the expression $(a-c)^{2} / 2 b$ means the consumer surplus $C S_{P C}$ in situation of perfect competition, i.e. when goods are on sale at the price equal to marginal costs. Thus, in situation of high fixed costs that exceed $12.8 \%$ of $C S_{P C}$ even the inevitable collusion of socially effective number of firms is preferable than competition of equilibrium number of firms.

The obtained boundary level of fixed costs is extremely high and is carried out quite seldom. But if it is known that the collusion is inevitable the lesser of two evils will be the transition from competition of excessive equilibrium number of firms to monopoly.

In case of monopoly social welfare is determined by the following formula:

$$
S W_{\text {mon }}=\frac{3}{8} \frac{(a-c)^{2}}{b}-f .
$$

We will now estimate the values of model parameters, when the difference

$$
S W_{\text {mon }}-S W_{\text {wo } / \text { col }}\left(n_{1}\right)=-\frac{1}{8} \frac{(a-c)^{2}}{b}-\frac{3}{2} f+\sqrt{\frac{(a-c)^{2} f}{b}}
$$

is positive. Let's define $z=(a-c) / \sqrt{b f}$ and explore

$$
g(z)=\frac{S W_{\text {mon }}-S W_{w o / c o l}\left(n_{1}\right)}{f}=-\frac{1}{8} z^{2}-\frac{3}{2}+z .
$$

If $g(z)$ is positive, monopoly is the lesser of two evils. By solving the inequality

$$
-\frac{1}{8} z^{2}+z-\frac{3}{2}>0
$$

we will get that $z \in(2 ; 6)$, which means that the inequality

$$
\frac{(a-c)^{2}}{b f}<36
$$

should be satisfied.

Thus, the transition to monopoly is better than competition of excessive equilibrium number of firms when

$$
f>\frac{1}{18} \cdot \frac{(a-c)^{2}}{2 b}=\frac{1}{18} \cdot C S_{P C} \approx 0.056 \cdot C S_{P C},
$$

i.e. when fixed costs exceeds $5.6 \%$ of consumer surplus in situation of perfect competition.

Thus, with a high share of the fixed component in the cost function we are able not to be afraid of reducing the number of firms to the socially effective level, despite increasing the collusion threat. Let's find out how the danger of collusion related to the share of fixed costs and characteristics of demand function. Let the equilibrium ratio of fixed and variable costs be the following:

$$
\alpha=\frac{F C}{V C}=\frac{f}{c q} .
$$

Let's suppose also that we know how many times the «choke price» (the maximum price that consumers are ready to pay for the product) exceeds the marginal costs:

$$
\gamma=\frac{a}{c} \text {. }
$$

Under linear demand and costs the optimal quantity of production is calculated by the formula

$$
q^{*}=\frac{1}{n+1} \cdot \frac{a-c}{b},
$$

and the equilibrium number of firms is equal to

$$
n_{1}=\sqrt{\frac{(a-c)^{2}}{b f}}-1
$$

So the expression (5) can be rewritten as follows:

$$
f=\alpha \cdot c q=\alpha \cdot c \frac{1}{n+1} \cdot \frac{a-c}{b}=\alpha c \frac{\sqrt{b f}}{a-c} \cdot \frac{a-c}{b}=\alpha c \sqrt{\frac{f}{b}}, f=\frac{\alpha^{2} c^{2}}{b} \text {. }
$$

As it follows from (4), (6), the collusion of socially effective number of firms is the lesser of evil compared to the excessive equilibrium number of firms when

$$
f>0.064 \frac{(a-c)^{2}}{b}=0.064 \frac{(\gamma-1)^{2} \cdot c^{2}}{b} .
$$

Using (6), we obtain the inequality

$$
\begin{gathered}
\frac{\alpha^{2} \cdot c^{2}}{b}>0.064 \frac{(\gamma-1)^{2} \cdot c^{2}}{b}, \alpha>0.253(\gamma-1), \\
\gamma<\bar{\gamma}=\frac{\alpha}{0.253}+1 \approx 3.9 \alpha+1 .
\end{gathered}
$$

Consequently, the risk of collusion is not critically dangerous if the difference between «choke price» and marginal costs does not exceed a certain critical value associated with the ratio of fixed and variable costs.

\section{Empirical research}

As it was shown above, the positive or negative correlation between concentration and social efficiency is connected with the share of fixed costs. It's possible to estimate it for the largest world corporations on the base of statistics presented at the Bloomberg terminal. Let's see for example the "Computer Hardware \& Services» 
industry in the 1998-2012 years. Converting original currencies into US dollars and taking into account inflation it's easy to use aggregate corporate data on revenues, costs, and profits to calculate the share of fixed costs by the following formula:

$$
\bar{\alpha}=\frac{F C}{T C}=1-\frac{V C}{T C}=1-\frac{V C}{T R-\pi} .
$$

Let's collect the annual shares of fixed costs (in percent) for several biggest corporations from 1998 till 2012, the mean value (M), and the standard deviation (SD) in the table 3. We can see that despite big difference between companies, and substantial fluctuations of sales, costs, and especially profits, the annual shares of fixed costs for all companies are very similar during economic boom and the dotcom crisis, gradual growth and the crisis of 2008-2009.

Table 3. The share of fixed costs in the «Computer Hardware \& Services» companies in 1998-2012, \%.

\begin{tabular}{|c|c|c|c|}
\hline & 00 & & \\
\hline & 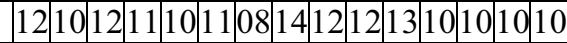 & & \\
\hline & 24 & 13 & 4 \\
\hline D & \begin{tabular}{|l|l|l|l|l|l|l|l|}
16 & 15 & 14 & 14 & 13 & 1 \\
\end{tabular} & 15 & \\
\hline & \begin{tabular}{|l|l|l|l|l|l|}
24 & 24 & 26 & 28 \\
\end{tabular} & 22 & 4 \\
\hline A & 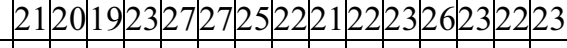 & 23 & 2 \\
\hline & 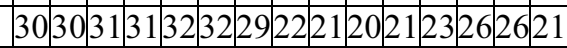 & 20 & 5 \\
\hline & $28|27| 28|31| 30|272625| 24 \mid 252725272$ & 27 & 2 \\
\hline Pan & 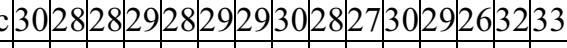 & 29 & 2 \\
\hline & 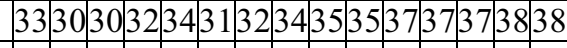 & 34 & 3 \\
\hline el & \begin{tabular}{|l|l|l|l|l|l|l|l|l|l|l|l|l|l|l|l|l|l|l|}
40 & 46 & 45 & 47 & 43 & 47 & 46 & 48 & 43 & 48 & 53 \\
\end{tabular} & 47 & 4 \\
\hline sco & \begin{tabular}{|l|l|l|l|l|l|l|l|l|l|l|l|l|l|}
59 & 58 & 59 & 52 & 59 & 63 & 61 & 57 & 57 & 54 & 55 & 57 & 55 & 55 \\
\end{tabular} & 57 & 3 \\
\hline 0 & \begin{tabular}{|l|l|l|l|l|l|l|l|l|l|l|l|l|l|}
80 & 81 & 85 & 81 & 82 & 74 & 53 & 38 & 53 & 55 & 55 & 5 \\
\end{tabular} & 64 & 15 \\
\hline icle & 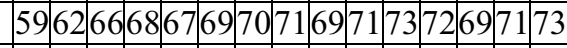 & 69 & 4 \\
\hline Microso & 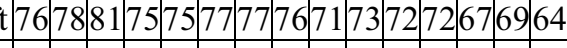 & & 5 \\
\hline$\Delta$ & 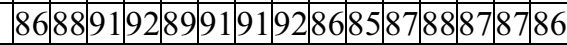 & & 2 \\
\hline
\end{tabular}

Let's find the critical ratio between «choke price» and marginal costs for several companies of the «Computer Hardware \& Services» industry and estimate for them the risk of possible collusion connected with transition from the equilibrium number of firms to the socially effective one (table 4 )

Table 4. Risk of possible collusion depending on the share of fixed costs.

\begin{tabular}{|c|c|c|c|c|}
\hline $\bar{\alpha}$ & $\alpha$ & Typical Company & $\bar{\gamma}$ & Risk \\
\hline 0.1 & 0.11 & Lenovo & 1.4 & Very high risk \\
\hline 0.25 & 0.33 & Sony, Apple & 2.3 & High risk \\
\hline 0.5 & 1 & Intel & 5 & Medium risk \\
\hline 0.75 & 3 & Microsoft & 13 & Low risk \\
\hline 0.9 & 9 & Adobe & 37 & No risk \\
\hline
\end{tabular}

We can see that the costs of collusion for companies engaged in production of computers and digital technologies (such as «Lenovo», «Sony», «Apple») are quite serious in the situation of limited competition. Therefore, the regulation of these markets is impractical. Moreover, the social planner should restrict the possible increasing of market power caused by the companies presented at the market.
On the other hand, for the companies engaged in software development («Microsoft», «Adobe», etc) the high share of R\&D fixed costs leads to the fact that the restriction of competition may be socially efficient, despite the increased risk of collusion.

It's possible to do similar empirical investigation for the other industries. Most of them don't have such a big deviation within themselves. Even outliers usually belong to the same group of firms as the whole industry. Moreover the results for most companies are very stable in time, despite economic growth and depressions. But there is a big difference between industries. So we need different mechanisms of their regulation.

There are several industries (include «Diversified Metal \& Mining», «Construction», «Oil \& Gas Operations», «Auto \& Trucks», «Electrical Equipment», «Diversified Chemicals», and «Food Processing») with low share of fixed costs, not exceeding $30 \%$. It means that it's very dangerous to regulate these industries by entry barriers if the regulator can't provide competition at such markets.

Some other industries such as «Personal Care», «Medical Supplies», «Electric Utilities» (we can also add here the sub-industry of software producers unlike hardware companies) due to large investments or R\&D costs have a big share of fixed costs. It means that there could be a significant effect of the number of firms decreasing, exceeding the collusion losses even if we can't avoid it.

Let's collect the minimum, maximum, and average shares of fixed costs for the biggest corporations of different industries in the table 5. Let's also include into the table the standard deviation of the fixed costs share within industries, and the critical ratio between «choke price» and marginal costs.

Table 5. The share of fixed costs for different industries.

\begin{tabular}{|c|c|c|c|c|c|}
\hline \multirow{2}{*}{ Industry } & \multicolumn{4}{|c|}{ The share of fixed costs, $\%$} & \multirow{2}{*}{$\bar{\gamma}$} \\
\hline & $\mathbf{M}$ & Min & Max & SD & \\
\hline Metals \& Mining & 15 & 4 & 34 & 8.8 & 1.7 \\
\hline Construction & 18 & 2 & 30 & 8.7 & 1.9 \\
\hline Oil \& Gas & 19 & 5 & 54 & 13.3 & 1.9 \\
\hline Auto \& Trucks & 20 & 13 & 28 & 4.3 & 2.0 \\
\hline Electrical Equipment & 25 & 12 & 44 & 9.9 & 2.3 \\
\hline Chemicals & 26 & 16 & 47 & 10.1 & 2.4 \\
\hline Food Processing & 29 & 4 & 54 & 15.8 & 2.6 \\
\hline Computers & 40 & 9 & 88 & 24.7 & 3.6 \\
\hline Personal Care & 42 & 22 & 65 & 13.8 & 3.8 \\
\hline Medical Supplies & 53 & 26 & 80 & 17.0 & 5.4 \\
\hline Electric Utilities & 61 & 39 & 80 & 12.1 & 7.1 \\
\hline
\end{tabular}

\section{Conclusions and policy implications}

The first result proposed in the paper is that socially effective number of firms is smaller than the equilibrium one for the wide spectre of demand and cost functions, and also for different strategies of companies' behavior. This proposition is satisfied for the markets where output of each company decreases when the number of firms increases, and the competition gets stronger. 
Thus the entry barriers, constructed by incumbent companies, do not always decrease social welfare. In some cases it's even good for government not to stimulate excessive competition but on the contrary to restrict the entry of new companies to the market.

At the same time there is a considerable danger of the increasing probability of collusion in a situation of number of firms limitation. So we compared the losses caused by duplicated fixed costs, and by possible collusion, and showed that collusion is the lesser of two evils if the gap between «choke price» and marginal costs is smaller than a certain critical value connected with the share of fixed costs. Thus, we should estimate if the real market value gamma is smaller than the obtained critical point. If so then it's possible to regulate market via entry barriers, otherwise - no.

There are also some other threats of entry limitation which should be taken into account. When the entry barriers system is organized through licenses and permissions it's very important to restrict corruption which is highly probable, especially if the licenses distribution is carried out by officials, but not via auction. Also, as the entry barriers lead to social welfare redistribution (consumer surplus reduces with the simultaneous increase of firms' profits) it's very important to design the effective tax mechanisms of withdrawal of rent, gained because of higher level of market power.

The research is supported by the RFBR grant №1606-00071, and the European Union's Seventh Framework Program FP7/07-13/ under REA grant agreement number 609642 .

\section{References}

1. J. Tirole, The Theory of Industrial Organization (MIT Press, 1988)
2. O. Shy, Industrial Organiztion: Theory and Applications (MIT Press, 1995)

3. D. Carlton, J. Perloff, Modern Industrial Organization (Addison-Wesley, 2000)

4. P. Belleflamme, M. Peitz, Industrial Organization. Markets and Strategies (Camb. Univ. Press, 2015)

5. N. Aizenberg, A. Filatov, Mathematical models of imperfect competition (ISU Press, 2012)

6. M. Spence, Rev. Econ. Stud., 43, 217-236 (1976)

7. A. Dixit, J. Stiglitz, AER, 67, 297-308 (1977)

8. C. von Weizsacker, Bell J. Econ., 11, 399-4 (1980)

9. K. Perry, J. Ind. Econ., 32, 313-330 (1984)

10. G. Mankiw, M. Whinston, RAND J. Econ., 17, 4858 (1986)

11. S. Berry, J. Waldfogel, RAND J. Econ., 3, 397-4 (1999)

12. C. Hsei, E. Moretti, J. Polit. Econ., 111, 1076-1121 (2003)

13. A. Hortacsu, C. Syverson, QJE, 119, 403-456 (2004)

14. P. Davis, J. Ind. Econ., 54, 293-321 (2006)

15. T. Bresnahan, P. Reiss, J. Polit. Econ., 99, 977-1009 (1991)

16. E. Zhelobodko, S. Kokovin, M. Parenti, J. Thisse, Econometrica, 8, 2765-2784 (2012)

17. V. Golikova, K. Gonchar, B. Kuznetsov, A. Yakovlev, Russia industry at at the crossroads: what prevents our firms to become competitive (HSE, Moscow, 2008)

18. J. Bain, Barriers to new competition (Harv. Univ. Press, 1956)

19. A. Jasquemin, M. Slade, Handbook of Industrial Organization (1989) 